\title{
Indicators of erythrocyte formation and degradation in rats with either vitamin A or iron deficiency
}

\author{
A.J.C. Roodenburg, ${ }^{*}$ C.E. West ${ }^{\dagger}{ }^{\text {Y. Beguin, }}{ }^{\dagger}$ J.E. Van Dijk, ${ }^{\S}$ H.G. Van Eijk, \\ J.J.M. Marx, ${ }^{\mathrm{TI}}$ and A.C. Beynen** \\ *Unilever Health Institute, Unilever Research Vlaardingen, Vlaardingen, The Netherlands; \\ ${ }^{\dagger}$ Division of Human Nutrition and Epidemiology, Wageningen Agricultural University, \\ Wageningen, The Netherlands and Department of International Health, Rollins School of \\ Public Health, Emory University, Atlanta, Georgia USA; "Department of Haematology, \\ University of Liege, Liege, Belgium; ${ }^{\S}$ Department of Veterinary Pathology, Veterinary Faculty, \\ Utrecht University, Utrecht, The Netherlands; "Department of Chemical Pathology, Medical \\ Faculty, Erasmus University Rotterdam, Rotterdam, The Netherlands; "Eijkman-Winkler Institute \\ and University Hospital Utrecht, Utrecht, The Netherlands; **Department of Laboratory Animal \\ Science, Veterinary Faculty, Utrecht University, Utrecht, The Netherlands
}

\begin{abstract}
Vitamin A deficiency produces anemia and altered iron status. In this study with rats we tested two hypotheses regarding vitamin A deficiency: (1) that it impairs erythropoiesis, leading to an increased red cell turnover, and (2) that it inhibits the glycosylation of transferrin. Erythropoietic activity was assessed indirectly by determining the myeloid:erythroid ratio in bone marrow smears, the number of erythroid colonies in the red pulp of spleen, the blood reticulocyte index, and zinc protoporphyrin and plasma transferrin receptor concentrations. Transferrin glycosylation was assessed by measuring the sialic acid content of transferrin. The effects of vitamin A deficiency were compared with those of iron deficiency. Iron deficiency produced anemia and low iron levels in organs. Vitamin A deficiency produced low levels of plasma and hepatic retinol, and it induced decreased plasma total iron-binding capacity and raised iron levels in tibia and spleen. Short- but not long-term iron deficiency reduced the number of erythroid colonies in spleen; vitamin A deficiency had no influence. Neither iron nor vitamin A deficiency influenced the myeloid:erythroid ratio in bone marrow smears and the blood reticulocyte production. Plasma transferrin receptor and erythrocyte zinc protoporphyrin concentrations were not affected by vitamin A deficiency but increased with iron deficiency. Vitamin A deficiency did not stimulate erythrocyte breakdown, as indicated by unaltered plasma lactate dehydrogenase activity and reduced plasma total bilirubin levels. Both vitamin A and iron deficiencies raised the proportion of multiple sialylated transferrins in plasma. Thus, we have not found evidence that vitamin A deficiency affects erythropoiesis and erythrocyte turnover. The iron accumulation in spleen and bone marrow may be related to reduced iron transport due to inhibition of transferrin synthesis rather than inhibition of transferrin sialylation. (J. Nutr. Biochem. 11:223-230, 2000) (C) Elsevier Science Inc. 2000. All rights reserved.
\end{abstract}

Keywords: vitamin A deficiency; iron deficiency; red cell metabolism; pathology; transferrin glycosylation; rats

\footnotetext{
Address correspondence to Dr. Annet J.C. Roodenburg, Unilever Health Institute, Unilever Research Vlaardingen, P.O. Box 114, $3130 \mathrm{AC}$ Vlaardingen, The Netherlands.

This research was funded by the Dutch Ministry of Education and Science through the Human Nutrition Biology Graduate Training Network.

Received May 17, 1996; accepted February 2, 2000.
}

\section{Introduction}

Vitamin A deficiency in humans is associated with anemia. ${ }^{1-6}$ In rats, vitamin A deficiency reduces the incorporation of radioactive iron into erythrocytes, ${ }^{7,8}$ alters red blood cell morphology, ${ }^{9,10}$ produces mild anemia, ${ }^{11-14}$ low- 
ers plasma total iron-binding capacity, ${ }^{13,15,16}$ increases iron absorption, $, 12,13$ and causes iron accumulation in spleen $^{10,13-15,16}$ and bone. ${ }^{13,15,16}$ Based on studies in rats, we have hypothesized ${ }^{15}$ that vitamin A deficiency impairs erythropoiesis, so that mild anemia with malformed red cells develops. The abnormal erythrocytes could be broken down at increased rates, causing accumulation of iron in the macrophages in spleen and bone marrow. The accumulation of iron could lead to low iron transport capacity as indicated by a decrease in plasma total iron-binding capacity; or transferrin synthesis could primarily be impaired in vitamin A deficiency.

We have tested this hypothesis in rats fed a diet deficient in vitamin A. The myeloid:erythroid ratio in bone marrow smears and the number of erythroid colonies in the red pulp of spleen were measured as indices of erythropoiesis. The ratio quantifies the rate of erythropoiesis relative to that of myelopoiesis. ${ }^{17}$ Erythropoietic activity was also assessed by measuring plasma transferrin receptor concentration ${ }^{18,19}$ and the reticulocyte index (i.e., the number of circulating reticulocytes corrected for the degree of anemia). Red cell degradation was estimated indirectly by measuring both plasma total bilirubin, which is derived from breakdown of hemoglobin, and plasma lactate dehydrogenase activity, which is in part derived from hemolysis. ${ }^{17}$ Functional iron deficiency was assessed by measuring zinc protoporphyrin, which is a precursor of heme in erythrocytes. ${ }^{20}$ Transferrin synthesis in vitamin A deficiency might be impaired at the level of its glycosylation ${ }^{21}$; this possibility was checked by determining the sialic acid content of transferrin.

In this study, the impact of vitamin A deficiency was compared and contrasted with that of iron deficiency so as to facilitate interpretation. Rats were sampled after 12 and 70 days of feeding a vitamin A- or iron-deficient diet. It was anticipated that sampling at the two time intervals would allow the primary and secondary effects of vitamin A deficiency on the indicators of erythrocyte formation and degradation to be distinguished.

\section{Materials and methods}

This study was approved and supervised by the animal welfare officer of Wageningen Agricultural University.

\section{Animals, housing, and diets}

Male Wistar rats (Cpb:WU), derived from a commercial breeder (Harlan CPB, Zeist, The Netherlands), were used. On arrival, the rats, aged 3 weeks, were housed in 12 groups of six animals in wire-topped, polycarbonate cages $(34.5 \times 22.5 \times 16 \mathrm{~cm})$ with a layer of sawdust as bedding. During the pre-experimental period of 2 weeks, all rats were fed the diet (Table 1) without added vitamin $\mathrm{A}$, but with adequate iron ( $35 \mathrm{mg}$ added iron $/ \mathrm{kg}$ feed). The vitamin A-deficient diet was fed to lower vitamin A stores and thus facilitate the development of vitamin A deficiency during the experimental period.

After the pre-experimental period (day 0), the rats were divided into three groups each of 24 rats so that body weight distributions of the groups were similar. The rats were then housed in groups of four animals in stainless steel cages with wire mesh bases $(30 \times$ $42 \times 19 \mathrm{~cm}$ ). One group received the control diet. This diet (Table 1) was formulated according to the nutrient requirements of rats. ${ }^{22}$ Another group continued to receive the vitamin A-deficient diet.
Table 1 Composition of the diets

\begin{tabular}{|c|c|c|c|}
\hline Ingredients & $\begin{array}{l}\text { Control } \\
\text { diet }\end{array}$ & $\begin{array}{c}\text { Vitamin A } \\
\text { deficient } \\
\text { diet }\end{array}$ & $\begin{array}{l}\text { Iron } \\
\text { deficient } \\
\text { diet }\end{array}$ \\
\hline Casein (g) & 151 & 151 & 151 \\
\hline Corn oil (g) & 25 & 25 & 25 \\
\hline Coconut fat (g) & 25 & 25 & 25 \\
\hline Glucose (g) & 709.2 & 709.2 & 709.2 \\
\hline Cellulose (g) & 30 & 30 & 30 \\
\hline $\mathrm{CaCO}_{3}(\mathrm{~g})$ & 12.4 & 12.4 & 12.4 \\
\hline $\mathrm{NaH}_{2} \mathrm{PO}_{4} \cdot 2 \mathrm{H}_{2} \mathrm{O}(\mathrm{g})$ & 15.1 & 15.1 & 15.1 \\
\hline $\mathrm{MgCO}_{3}(\mathrm{~g})$ & 1.4 & 1.4 & 1.4 \\
\hline $\mathrm{KCl}(\mathrm{g})$ & 1.0 & 1.0 & 1.0 \\
\hline $\mathrm{KHCO}_{3}(\mathrm{~g})$ & 7.7 & 7.7 & 7.7 \\
\hline $\mathrm{FeSO}_{4} \cdot 7 \mathrm{H}_{2} \mathrm{O}(\mathrm{mg})$ & 174 & 174 & 17.4 \\
\hline $\begin{array}{l}\text { Vitamin A preparation* } \\
\text { (mg) }\end{array}$ & 8 & - & 8 \\
\hline Mineral premix ${ }^{\dagger}(\mathrm{g})$ & 10 & 10 & 10 \\
\hline Vitamin premix ${ }^{\ddagger}(\mathrm{g})$ & 12 & 12 & 12 \\
\hline
\end{tabular}

${ }^{*}$ Rovimix A 500 ${ }^{\circledR}, 150$ retinol equivalents/mg (F. Hoffmann-La Roche \& Co. Ltd., Basle, Switzerland), consisting of retinyl acetate and retinyl palmitate.

The mineral premix consisted of (mg): $\mathrm{MnO}_{2}, 79 ; \mathrm{ZnSO}_{4} \cdot \mathrm{H}_{2} \mathrm{O}, 33$; $\mathrm{NiSO}_{4} \cdot 6 \mathrm{H}_{2} \mathrm{O}, 13 ; \mathrm{NaF}, 2 ; \mathrm{Kl}, 0.2 ; \mathrm{CuSO}_{4} \cdot 5 \mathrm{H}_{2} \mathrm{O}, 15.7 ; \mathrm{Na}_{2} \mathrm{SeO}_{3}$. $5 \mathrm{H}_{2} \mathrm{O}, 0.3 ; \mathrm{CrCl}_{3} \cdot 6 \mathrm{H}_{2} \mathrm{O}, 1.5 ; \mathrm{SnCl}_{2} \cdot 6 \mathrm{H}_{2} \mathrm{O}, 1.9 ; \mathrm{NH}_{4} \mathrm{VO}_{3}, 0.2$; corn meal, $9,853.2$.

抽e vitamin premix consisted of (mg): thiamin, 4; riboflavin, 3; niacin, 20; D,L-calcium pantothenate, 17.8; pyridoxine, 6; cyanocobalamin, 50; choline chloride, 2,000; folic acid, 1; biotin, 2; menadione, 0.05; D,L- $\alpha$-tocopheryl acetate, 60; cholecalciferol, 0.025; corn meal, 9,836.125.

The third group was transferred to the iron-deficient diet containing $3.5 \mathrm{mg}$ added iron $/ \mathrm{kg}$ feed (Table 1). Analyzed iron concentrations of the diets were as follows ( $\mathrm{mg} / \mathrm{kg}$ feed): control diet, 45 ; vitamin A-deficient diet, 45; iron-deficient diet, 10. The purified diets were in powdered form and stored at $4{ }^{\circ} \mathrm{C}$ until used for feeding. The animals had free access to feed and demineralized water. Feed intakes, corrected for feed spillage, were measured per cage twice weekly, and individual body weights were measured once a week. A controlled light/dark cycle (light on: 6:00 AM-6:00 $\mathrm{PM})$, temperature $\left(20-22^{\circ} \mathrm{C}\right)$, and relative humidity $(50-60 \%)$ were maintained in the animal room.

\section{Collection of samples}

On days 12 and 70, 12 animals taken from three cages of each dietary group were sacrificed. For a period of 7 days prior to days 12 and 70, the animals to be sacrificed were housed individually in metabolism cages $\left(314 \mathrm{~cm}^{2} \times 12 \mathrm{~cm}\right)$. During the last 4 days while the rats were in the metabolism cages, intake of feed and water was measured and feces and urine collected quantitatively. Feces were stored at $-20^{\circ} \mathrm{C}$ until analysis; urine was discarded. Between 9:00 and 11:00 AM, heparinized blood was obtained from the nonfasting rats by orbital puncture while they were under diethyl ether anesthesia. The blood was stored at $0^{\circ} \mathrm{C}$ for hematologic examination and reticulocyte and differential white blood cell counting on the same day. The plasma collected was stored at $-20^{\circ} \mathrm{C}$ until analysis, except for $250 \mu \mathrm{L}$, which was stored at $-80^{\circ} \mathrm{C}$ prior to analysis of retinol. Immediately after bleeding, the anesthetized rats were decapitated. The kidneys, liver, spleen, and two hindlegs were removed. The organs were weighed and prepared for histology or stored at $-20^{\circ} \mathrm{C}$ until analysis. 
A

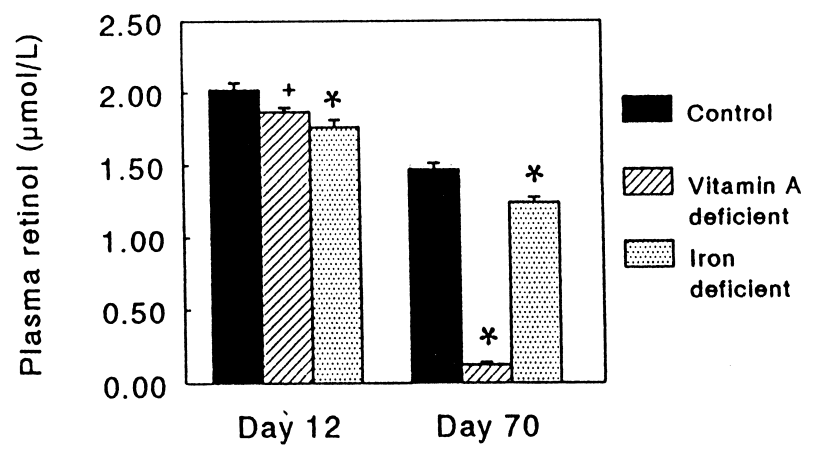

B

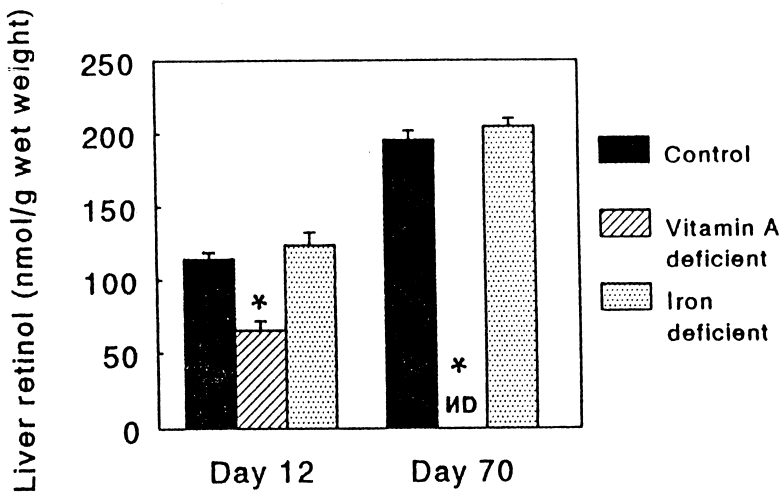

Figure 1 Plasma (A) and liver (B) retinol concentrations at days 12 and 70 of the experiment. Bars represent means of 12 animals per group and their standard error. Differences versus the control group: ${ }^{+} P<0.05 ;{ }^{*} P<0.001$.

\section{Histologic examination}

The right kidney, half of the spleen, and a portion of the left lateral liver lobe were fixed in 10\% neutralized formalin (Baker, Deventer, The Netherlands). Slides were prepared and stained with a hematoxylin/eosine solution or by the Perls' Prussian Blue reaction (potassium ferrocyanide and neutral red) according to conventional techniques. ${ }^{23}$

All slides were examined in a strictly standardized manner by one person who was blinded to treatment modality. Kidney slides were examined for the presence of calcification and basophilic cells, which may represent early stages in the morphogenesis of renal neoplasms. ${ }^{24}$ In spleen slides the number of erythroid colonies were counted and liver slides were checked for portal or periportal round cell infiltrations. The location of iron was described only for the histologic slides corresponding to day 70 because iron was not detectable in the slides corresponding to day 12. The histologic variables were quantified as scores $(0,1,2$, or 3 ) except for the number of erythroid colonies in the spleen and the percentage of hepatic iron that was located in macrophages.

Immediately after sacrifice, the right tibia was rid of adhering tissue and cut open with a small pair of scissors. The bone marrow was placed directly on a glass slide with a scalpel and gently spread with another slide held at an angle of approximately $45^{\circ} \mathrm{C}$. After drying, the bone marrow smears were fixed and stained according to either the May-Grünwald Giemsa (eosin-methylene blue/azur eosin-methylene blue) staining method or the Kaplan iron staining method (potassium ferrocyanide and saffranin) using conventional techniques. ${ }^{24}$ A subsample of bone marrow smears was evaluated by differentially counting 300 to 400 cells. The location of iron in the smears was described.

\section{Hematology}

Hemoglobin concentration, hematocrit, red blood cell count, mean corpuscular hemoglobin concentration, and mean cell volume were measured with a blood cell counter (Model K-1000, Sysmex, IJsselstein, The Netherlands). Zinc erythrocyte protoporphyrin was determined in whole blood with a hematofluorometer (AVIV Biomedical 206, Lakewood, NJ USA). Differential counting of white blood cells was done in blood smears. In a portion of the smears, the number of reticulocytes per 1,000 cells was counted after staining with methylene blue. Reticulocyte production index was calculated as described by Hillman and Finch. ${ }^{25}$

\section{Chemical analyses}

Plasma iron concentrations and total iron-binding capacity were determined spectrophotometrically using a commercial test kit
(Roche Nederland, Mijdrecht, The Netherlands). Plasma total bilirubin, lactate dehydrogenase activity, and aspartate aminotransferase activity were also determined with commercial test kits (Roche Nederland). Plasma transferrin receptor concentrations were measured as described by Beguin et al. ${ }^{18}$ Transferrin microheterogeneity was determined with an isoelectric focusing technique and densitometry. ${ }^{26}$ Iron was measured by flame atomic absorption spectrometry following wet ashing with nitric acid for feed or dry ashing for liver, feces, spleen, left kidney, and tibia.

Plasma and liver retinol levels were measured by reversed phase high performance liquid chromatography (HPLC) as described by Roodenburg et al. ${ }^{13}$

\section{Statistical analysis}

For each time interval, the groups fed either the vitamin A-deficient or iron-deficient diet were compared with the control group. For the continuous variables, contrasts with pooled variances based on Student's $t$-test were used for comparison of group means; the variables were found to be distributed normally as based on Kolmogorov-Smirnov goodness of fit tests. The effects of the experimental diets on the histologic scores were evaluated with the nonparametric Mann-Whitney-Rank test. A pre-set $P$-value of $5 \%$ was used throughout.

\section{Results}

\section{Vitamin A status}

Plasma and hepatic retinol levels at day 12 were reduced in the vitamin A-deficient group compared with the control group (Figure 1). After 70 days, liver retinol was undetectable and plasma retinol lowered by $85 \%$ in rats given the vitamin A-deficient diet. In the rats fed the low iron diet, plasma, but not hepatic retinol, levels were reduced (Figure 1).

\section{Body weight, organ weights, and feed intake}

There were no diet effects on body weight and weights of kidney, spleen, and tibia (Table 2). Liver weight was reduced after either feeding the vitamin A- or iron-deficient diet for 70 days. Feed intake over the period of 67 to 70 days was reduced in both the vitamin A-deficient (14.3 SE 0.4 $\mathrm{g} / \mathrm{d}, P<0.001)$ and iron-deficient groups $(16.0 \mathrm{SE} 0.3 \mathrm{~g} / \mathrm{d}$, $P=0.027)$, when compared with the control group $(17.3$ SE $0.5 \mathrm{~g} / \mathrm{d}$ ). 
Table 2 Body and organ weights (g)

\begin{tabular}{|c|c|c|c|c|c|c|}
\hline & \multicolumn{3}{|c|}{ Day 12} & \multicolumn{3}{|c|}{ Day 70} \\
\hline & Control diet & Vitamin A deficient diet & Iron deficient diet & Control diet & Vitamin A deficient diet & Iron deficient diet \\
\hline Body weight & $199.7 \pm 4.9$ & $203.5 \pm 3.3$ & $193.3 \pm 5.2$ & $370.3 \pm 7.5$ & $350.8 \pm 7.8$ & $371.7 \pm 7.9$ \\
\hline Liver & $9.33 \pm 0.31$ & $9.23 \pm 0.29$ & $8.51 \pm 0.26$ & $12.28 \pm 0.44$ & $10.05 \pm 0.20^{b}$ & $11.34 \pm 0.22^{a}$ \\
\hline Kidney & $0.75 \pm 0.03$ & $0.75 \pm 0.01$ & $0.70 \pm 0.02$ & $0.97 \pm 0.08$ & $1.05 \pm 0.02$ & $1.03 \pm 0.02$ \\
\hline Spleen & $0.54 \pm 0.04$ & $0.48 \pm 0.02$ & $0.48 \pm 0.03$ & $0.64 \pm 0.03$ & $0.57 \pm 0.03$ & $0.66 \pm 0.04$ \\
\hline Tibia & $0.275 \pm 0.007$ & $0.277 \pm 0.004$ & $0.268 \pm 0.006$ & $0.462 \pm 0.012$ & $0.482 \pm 0.019$ & $0.467 \pm 0.018$ \\
\hline
\end{tabular}

Means are given with standard errors of the mean $(n=12)$. Organ and tibia weights refer to wet weight. When values differ significantly from the control group within time intervals, this is indicated as ${ }^{\mathrm{a}} P<0.05,{ }^{\mathrm{b}} P<0.001$.

Mean body weight at day 0 was $128.7 \pm 2.6 \mathrm{~g}$.

\section{Histology of organs}

The spleen slides were examined to assess extramedullary erythropoiesis, and liver and kidney slides were studied to detect any pathologic changes. Special attention was paid to possible calculi in kidney, because bladder and kidney stone formation may be stimulated by lack of vitamin A. ${ }^{27,28}$ The location of iron in kidney, liver, and spleen slides was described because it could provide clues as to mechanisms that underlie the impairment of iron metabolism in vitamin A deficiency. No iron was detected in all slides from the iron-deficient group.

Immunologic activity as indicated by round cell infiltrations with or without cell necrosis was seen both at the portal site of the liver lobules and in the region of the terminal veins. There was no effect of diet on the incidence of round cell infiltrations. Iron was detectable only in the control and vitamin A-deficient groups and at day 70 of the study only, most of it being located in the Kupffer cells. Only a small percentage $(2.5 \%)$ of the iron was in the hepatocytes; this percentage did not differ between the vitamin A-deficient and control groups.

Calcification and basophilic cells were seen in the kidneys of all three groups at the two time intervals, the incidences increasing with age. There were no differences between the dietary groups. Iron was located mainly in the cortex in the tubuli contorti. At these sites iron was seen in the nucleus, as grains in the cytoplasm, and in macrophages. Iron-positive stain was associated with the appearance of calculi, both in the medulla and the cortex. The presence of iron was not different between the vitamin A-deficient group and the control group.

Extramedullary erythropoiesis was estimated by counting erythroid colonies in the red pulp of the spleen. Splenic erythropoiesis was more pronounced at day 12 than at day 70 of the experiment. The number of erythroid colonies, however, was relatively low in the iron-deficient rats at day $12(P<0.001)$, an effect that disappeared at day 70 . No effect of vitamin A deficiency on extramedullary erythropoiesis was detected. Splenic iron was located in the macrophages; no influence of vitamin A deficiency was observed.

\section{Iron status}

In the group fed the low iron diet, blood hemoglobin, hematocrit, and mean cell volume were decreased, whereas zinc protoporphyrin was increased (Table 3). Red blood cell count was increased and mean corpuscular hemoglobin concentration decreased after 70 days of feeding the low

Table 3 Hematologic indices

\begin{tabular}{|c|c|c|c|c|c|c|}
\hline & \multicolumn{3}{|c|}{ Day 12} & \multicolumn{3}{|c|}{ Day 70} \\
\hline & $\begin{array}{l}\text { Control } \\
\text { diet }\end{array}$ & $\begin{array}{c}\text { Vitamin A } \\
\text { deficient } \\
\text { diet }\end{array}$ & $\begin{array}{c}\text { Iron } \\
\text { deficient } \\
\text { diet }\end{array}$ & $\begin{array}{l}\text { Control } \\
\text { diet }\end{array}$ & $\begin{array}{c}\text { Vitamin A } \\
\text { deficient } \\
\text { diet }\end{array}$ & $\begin{array}{c}\text { Iron } \\
\text { deficient } \\
\text { diet }\end{array}$ \\
\hline Hemoglobin (mmol/L) & $8.51 \pm 0.07$ & $8.38 \pm 0.10$ & $7.38 \pm 0.11^{c}$ & $9.48 \pm 0.07$ & $9.61 \pm 0.09$ & $8.10 \pm 0.16^{c}$ \\
\hline Hematocrit & $0.43 \pm 0.006$ & $0.43 \pm 0.005$ & $0.37 \pm 0.007^{c}$ & $0.49 \pm 0.004$ & $0.49 \pm 0.006$ & $0.43 \pm 0.007^{\circ}$ \\
\hline Red blood cell count $\left(\times 10^{12} / \mathrm{L}\right)$ & $6.5 \pm 0.1$ & $6.2 \pm 0.1$ & $6.2 \pm 0.1$ & $7.8 \pm 0.1$ & $7.9 \pm 0.1$ & $8.2 \pm 0.1^{\mathrm{b}}$ \\
\hline Mean cell volume (fL) & $66 \pm 0.8$ & $69 \pm 0.9$ & $60 \pm 0.9^{c}$ & $63 \pm 0.8$ & $63 \pm 0.8$ & $53 \pm 1.3^{c}$ \\
\hline $\begin{array}{l}\text { Mean corpuscular hemoglobin concentration } \\
(\mathrm{mmol} / \mathrm{L})\end{array}$ & $19.9 \pm 0.1$ & $19.7 \pm 0.1$ & $19.9 \pm 0.1$ & $19.3 \pm 0.1$ & $19.5 \pm 0.1$ & $18.9 \pm 0.1^{\mathrm{b}}$ \\
\hline $\begin{array}{l}\text { Zinc protoporphyrin concentration } \\
(\mathrm{mmol} / \mathrm{mol} \mathrm{Hb})\end{array}$ & $0.32 \pm 0.01$ & $0.31 \pm 0.01$ & $0.37 \pm 0.01^{b}$ & $0.30 \pm 0.01$ & $0.30 \pm 0.01$ & $0.42 \pm 0.02^{c}$ \\
\hline Reticulocytes (\% of red cell count) & $0.01 \pm 0.006$ & $0.03 \pm 0.004^{a}$ & $0.02 \pm 0.004$ & $0.04 \pm 0.007$ & $0.03 \pm 0.006$ & $0.04 \pm 0.004$ \\
\hline Production index ${ }^{*}$ & $1.0 \pm 0.6$ & $3.0 \pm 0.5^{a}$ & $1.3 \pm 0.2$ & $3.7 \pm 0.6$ & $3.4 \pm 0.6$ & $2.1 \pm 0.3$ \\
\hline
\end{tabular}

*Reticulocyte production index was calculated as $\{$ (reticulocytes $\times 100) \times \mathrm{Ht} / \mathrm{normal} \mathrm{Ht}\} /$ maturation index, with normal hematocrit $(\mathrm{Ht})$ taken to be 0.43 at day 12 and 0.49 at day 70 . Maturation index, a measure for the prolongation of maturation time of circulating blood reticulocytes that occurs with anemia, was 1 for control and vitamin A deficient groups and 1.5 in iron deficient groups. ${ }^{23}$

Means are given with standard errors of the mean ( $n=12$ except for reticulocytes: d12, $n=4$ and d70, $n=6)$. When values differ significantly from the control group within the time interval, this is indicated as ${ }^{a} P<0.05,{ }^{b} P<0.01,{ }^{c} P<0.001$. 


\begin{tabular}{|c|c|c|c|c|c|c|}
\hline & \multicolumn{3}{|c|}{ Day 12} & \multicolumn{3}{|c|}{ Day 70} \\
\hline & $\begin{array}{l}\text { Control } \\
\text { diet }\end{array}$ & $\begin{array}{l}\text { Vitamin A } \\
\text { deficient diet }\end{array}$ & $\begin{array}{c}\text { Iron } \\
\text { deficient diet }\end{array}$ & $\begin{array}{l}\text { Control } \\
\text { diet }\end{array}$ & $\begin{array}{l}\text { Vitamin A } \\
\text { deficient diet }\end{array}$ & $\begin{array}{c}\text { Iron } \\
\text { deficient diet }\end{array}$ \\
\hline Plasma iron ( $\mu \mathrm{mol} / \mathrm{L})$ & $45.9 \pm 2.2$ & $40.0 \pm 1.8^{\mathrm{a}}$ & $14.0 \pm 1.0^{\mathrm{c}}$ & $34.8 \pm 1.0$ & $35.5 \pm 1.0$ & $26.6 \pm 2.5^{b}$ \\
\hline Total iron binding capacity $(\mu \mathrm{mol} / \mathrm{L})$ & $100.9 \pm 2.2$ & $98.8 \pm 2.3$ & $125.5 \pm 2.8^{\mathrm{c}}$ & $97.7 \pm 1.9$ & $90.1 \pm 1.7^{b}$ & $121.2 \pm 2.1^{\mathrm{c}}$ \\
\hline Transferrin saturation (\%) & $45.8 \pm 2.7$ & $40.7 \pm 2.0$ & $11.3 \pm 1.0^{\mathrm{C}}$ & $35.7 \pm 0.9$ & $39.5 \pm 1.2$ & $22.2 \pm 2.2^{\mathrm{C}}$ \\
\hline $\begin{array}{l}\text { Plasma transferrin receptor concentration } \\
(\mathrm{ng} / \mathrm{mL})\end{array}$ & $3,333 \pm 165$ & $3,233 \pm 282$ & $4,242 \pm 319^{a}$ & $2,356 \pm 193$ & $2,216 \pm 139$ & $3,733 \pm 261^{\circ}$ \\
\hline
\end{tabular}

Means are given with standard errors of the mean $(n=12)$. When values differ significantly from the control group within time intervals, this is indicated as ${ }^{\mathrm{a}} P<0.05,{ }^{\mathrm{b}} P<0.01,{ }^{\mathrm{c}} P<0.001$.

iron diet. Feeding the vitamin A-deficient diet had no significant effect on hematologic indices, except for the increase in reticulocyte count at day 12.

Plasma iron concentrations at day 12 , but not at day 70 , were reduced in rats fed the vitamin A-deficient diet (Table 4 ). Feeding the low iron diet produced low plasma iron concentrations at both days 12 and 70, lower concentration being greater at day 12 . Total iron-binding capacity at day 70 was significantly reduced in vitamin A-deficient rats. Total iron-binding capacity and plasma transferrin receptor levels were increased, whereas transferrin saturation was reduced after consumption of the low iron diet.

Iron concentrations of liver, kidney, spleen, and tibia were reduced after 12 and 70 days feeding the low iron diet (Table 5). The iron concentration of liver at day 12 and that of both spleen and tibia at day 70 was significantly increased in the vitamin A-deficient group.

In the control and vitamin A-deficient groups the efficiency of iron absorption was similar and decreased with time (Figure 2). In the rats with iron deficiency the percentage of dietary iron absorbed was raised.

\section{Blood smears}

Differential counting of white blood cells was performed to indicate signs of infection. Vitamin A deficiency enhances the severity of infection. ${ }^{29}$ The leukocyte composition in blood smears was as follows: basophils, 0\%; eosinophils, $0.5 \%$ (range $0-3 \%$ ); band cells, $0 \%$; polymorphonuclear cells, $15.5 \%$ (range 2-36\%); lymphocytes, $84 \%$ (range 64-98\%); and monocytes, 0\%. There were no systematic differences between dietary groups or between time intervals. The differential counts of each animal were within the range considered normal ${ }^{30,31}$ so that the rats used appeared to be free of infection.

\section{Bone marrow smears}

The results of differential cell counting and localization of iron in bone marrow are given in Table 6. All values are within limits considered normal. ${ }^{32,33}$ No differences between the dietary groups could be detected. Iron-positive stain was not detectable in bone marrow slides from the iron-deficient rats.

\section{Indicators of erythrocyte breakdown and liver damage}

Plasma lactate dehydrogenase activity, an indicator of erythrocyte degradation, was not affected by feeding the experimental diets, whereas the other indicator, plasma bilirubin, was reduced in the vitamin A-deficient group, but only at day 70 (Table 7). Plasma aspartate aminotransferase activity, an index of tissue damage, especially liver damage, ${ }^{34}$ was not affected by diet type, except for the small increase at day 70 that was seen in the iron-deficient group.

\section{Transferrin microheterogeneity}

The relative occurrence of the 1-, 2-, 3-, and 4-sialo transferrin fractions in plasma is given in Table 8. Feeding the experimental diets for 12 days did not affect the pattern of sialo transferrin fractions. However, after 70 days of feeding either the vitamin A-deficient or iron-deficient diet, there was a significant increase in $(3+4)$ sialated transferrins at the expense of $(1+2)$ sialated transferrins as

Table 5 Iron concentration in tissues ( $\mu \mathrm{mol} / \mathrm{g}$ dry weight)

\begin{tabular}{|c|c|c|c|c|c|c|}
\hline & \multicolumn{3}{|c|}{ Day 12} & \multicolumn{3}{|c|}{ Day 70} \\
\hline & Control diet & $\begin{array}{c}\text { Vitamin A } \\
\text { deficient diet }\end{array}$ & $\begin{array}{l}\text { Iron deficient } \\
\text { diet }\end{array}$ & Control diet & $\begin{array}{c}\text { Vitamin A } \\
\text { deficient diet }\end{array}$ & $\begin{array}{l}\text { Iron deficient } \\
\text { diet }\end{array}$ \\
\hline Liver & $3.92 \pm 0.26$ & $5.62 \pm 0.56^{b}$ & $2.00 \pm 0.23^{b}$ & $8.01 \pm 0.66$ & $8.68 \pm 0.32$ & $2.35 \pm 0.59^{c}$ \\
\hline Kidney & $4.47 \pm 0.18$ & $4.36 \pm 0.17$ & $3.26 \pm 0.10^{c}$ & $6.27 \pm 0.45$ & $5.39 \pm 0.43$ & $3.41 \pm 0.20^{\circ}$ \\
\hline Spleen & $10.74 \pm 0.49$ & $12.14 \pm 0.69$ & $8.63 \pm 0.54^{a}$ & $29.75 \pm 1.77$ & $44.61 \pm 6.35^{b}$ & $10.60 \pm 0.34^{b}$ \\
\hline Tibia & $1.12 \pm 0.04$ & $1.20 \pm 0.04$ & $0.78 \pm 0.03^{c}$ & $1.28 \pm 0.04$ & $1.55 \pm 0.08^{b}$ & $0.80 \pm 0.05^{c}$ \\
\hline
\end{tabular}

Means are given with standard errors of the mean $(n=12)$. When values differ significantly from the control group within time intervals, this is indicated as ${ }^{\mathrm{a}} \mathrm{P}<0.05,{ }^{\mathrm{b}} \mathrm{P}<0.01,{ }^{\mathrm{c}} \mathrm{P}<0.001$. 


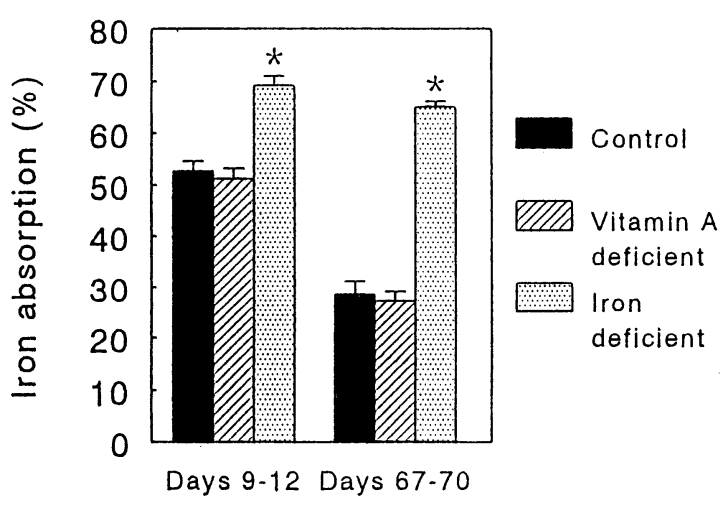

Figure 2 Apparent iron absorption for days 9 through 12 and days 67 through 70 of the experiment. Apparent absorption was calculated as iron ingested minus that excreted in feces and expressed as percentage of intake. Bars represent means of 12 animals per group and their standard error. Differences versus the control group: ${ }^{*} P<0.001$.

illustrated by the decreased $(1+2)$-sialo transferrin: $(3+4)$ sialo transferrin ratio.

\section{Discussion}

In essence, the observed effects of feeding the diets deficient in vitamin A or iron confirmed our earlier findings. ${ }^{13,15}$ The low iron diet produced anemia within 12 days, reduced plasma and organ iron concentrations, and increased apparent iron absorption and total iron-binding capacity. In contrast to our previous study, ${ }^{13}$ vitamin A deficiency in this study did not lower blood hemoglobin levels. However, the iron and vitamin A status of the rats in the present study, as indicated by the higher liver iron stores and slower progress of vitamin A deficiency, was higher than that in the previous study. ${ }^{13}$ Nevertheless, vitamin A deficiency did decrease total iron-binding capacity and increased the amount of iron in tibia and spleen, where it was localized mainly in macrophages. The deficiencies of vitamin $\mathrm{A}$ and iron that were induced may be considered relatively mild. In the deficient rats, body weight gain was not affected and the kidneys and liver of these rats did not show pathologic changes that differed from those in the control rats.

We have hypothesized that vitamin A deficiency impairs erythropoiesis, resulting in the formation of abnormally shaped red cells. However, neither hemoglobin concentration nor mean cell volume or mean corpuscular hemoglobin concentration were influenced by vitamin A deficiency. There was no evidence for changes in extramedullary erythropoiesis, as assessed by counting the number of erythroid colonies in spleen. In rats with mild iron deficiency anemia, aged 18 weeks, there was an increase in early erythroblasts in spleen. ${ }^{35}$ However, the number of erythroid colonies in the red pulp of spleen was decreased at day 12 in the iron-deficient rats. It is possible that acute and long-term effects of iron deficiency anemia on extramedullary erythropoiesis differ. The differential counting of bone marrow cells, with results within the normal range, ${ }^{31,32}$ revealed no effect of diet on the myeloid:erythroid ratio. The lack of effect of iron deficiency was unexpected because this condition is known to increase erythropoietic activity. ${ }^{36}$ In any event, it can be concluded that contrary to our hypothesis, we were not able to demonstrate an effect of vitamin A deficiency on erythropoiesis.

Further measurements also indicated that vitamin A deficiency did not influence the activity of the erythropoietic system. Transferrin receptors in the body are mainly situated in bone marrow and circulating plasma transferrin receptor concentration is a measure for erythropoietic activity. ${ }^{18}$ As would be expected, plasma transferrin receptor

Table 6 Differential cell counts and location of iron-positive stain in bone marrow smears (\% of total cells)

\begin{tabular}{|c|c|c|c|c|}
\hline & \multirow{2}{*}{$\frac{\text { Day } 12}{\text { Control diet }}$} & \multicolumn{3}{|c|}{ Day 70} \\
\hline & & Control diet & $\begin{array}{c}\text { Vitamin A } \\
\text { deficient diet }\end{array}$ & $\begin{array}{l}\text { Iron deficient } \\
\text { diet }\end{array}$ \\
\hline Total erythropoietic cells & $29.0 \pm 6.3$ & $32.5 \pm 3.5$ & $29.3 \pm 4.6$ & $27.8 \pm 4.3$ \\
\hline Total myelopoietic cells & $42.5 \pm 7.0$ & $43.0 \pm 6.9$ & $50.3 \pm 6.4$ & $47.3 \pm 3.3$ \\
\hline Myeloblasts & $4.3 \pm 0.9$ & $3.8 \pm 1.2$ & $1.8 \pm 0.3$ & $4.5 \pm 1.2$ \\
\hline Promyelocytes & $1.3 \pm 0.3$ & $1.3 \pm 0.6$ & $1.5 \pm 0.8$ & $1.3 \pm 0.6$ \\
\hline Myelocytes & $2.0 \pm 1.3$ & $2.5 \pm 0.3$ & $4.3 \pm 1.5$ & $4.3 \pm 1.3$ \\
\hline Metamyelocytes & $1.8 \pm 1.0$ & $0.0 \pm 0.0$ & $2.5 \pm 1.4$ & $1.3 \pm 0.3$ \\
\hline Bandcells & $7.3 \pm 1.1$ & $7.0 \pm 0.8$ & $7.8 \pm 1.7$ & $8.5 \pm 1.5$ \\
\hline Segmented neutrophils & $23.0 \pm 6.3$ & $25.3 \pm 5.7$ & $30.0 \pm 8.2$ & $25.5 \pm 2.6$ \\
\hline Eosinophils & $3.0 \pm 1.3$ & $3.3 \pm 0.9$ & $2.5 \pm 0.8$ & $2.0 \pm 0.8$ \\
\hline Basophils & $0.0 \pm 0.0$ & $0.0 \pm 0.0$ & $0.0 \pm 0.0$ & $0.0 \pm 0.0$ \\
\hline Lymphocytes & $27.0 \pm 6.9$ & $22.0 \pm 7.6$ & $18.3 \pm 7.8$ & $19.3 \pm 7.5$ \\
\hline Plasma cells & $0.0 \pm 0.0$ & $0.0 \pm 0.0$ & $0.0 \pm 0.0$ & $0.8 \pm 0.6$ \\
\hline Monocytes & $0.8 \pm 0.6$ & $1.3 \pm 0.3$ & $0.8 \pm 0.6$ & $1.8 \pm 0.6$ \\
\hline Myeloid:erythroid ratio & $1.7 \pm 0.6$ & $1.4 \pm 0.3$ & $1.8 \pm 0.3$ & $1.8 \pm 0.2$ \\
\hline \multicolumn{5}{|l|}{ Iron located in } \\
\hline Reticuloendothelium & Trace & $++/+$ & ++ & Negative \\
\hline Sideroblasts & + & Trace & Trace & Negative \\
\hline Siderocytes & + & Trace & Negative & Negative \\
\hline
\end{tabular}

Means are given with standard errors of the mean ( $n=4$ or 6$)$.

Mast cells and megakaryocytes were not included in the differential counting of 300 to 400 cells per bone marrow smear. 
Vitamin A and red cell metabolism: Roodenburg et al.

Table 7 Plasma total bilirubin concentration, lactate dehydrogenase, and aspartate aminotransferase activity

\begin{tabular}{|c|c|c|c|c|c|c|}
\hline & \multicolumn{3}{|c|}{ Day 12} & \multicolumn{3}{|c|}{ Day 70} \\
\hline & Control diet & $\begin{array}{c}\text { Vitamin A } \\
\text { deficient diet }\end{array}$ & $\begin{array}{l}\text { Iron deficient } \\
\text { diet }\end{array}$ & Control diet & $\begin{array}{c}\text { Vitamin A } \\
\text { deficient diet }\end{array}$ & $\begin{array}{c}\text { Iron deficient } \\
\text { diet }\end{array}$ \\
\hline $\begin{array}{l}\text { Total plasma bilirubin concentration }(\mu \mathrm{mol} / \mathrm{L}) \\
\text { Plasma lactate dehydrogenase activity }(\mathrm{U} / \mathrm{L}) \\
\text { Aspartate aminotransferase activity }(\mathrm{U} / \mathrm{L})\end{array}$ & $\begin{aligned} 15.4 & \pm 1.9 \\
149.6 & \pm 10.5 \\
62.7 & \pm 5.5\end{aligned}$ & $\begin{aligned} 14.5 & \pm 1.4 \\
157.7 & \pm 14.6 \\
65.5 & \pm 5.0\end{aligned}$ & $\begin{aligned} 16.4 & \pm 1.8 \\
166.3 & \pm 31.8 \\
78.0 & \pm 6.6\end{aligned}$ & $\begin{aligned} 13.9 & \pm 2.2 \\
245.9 & \pm 19.3 \\
53.9 & \pm 1.5\end{aligned}$ & $\begin{aligned} 8.1 & \pm 0.9^{a} \\
247.7 & \pm 26.8 \\
50.5 & \pm 2.6\end{aligned}$ & $\begin{aligned} 11.4 & \pm 1.1 \\
208.5 & \pm 8.6 \\
61.4 & \pm 1.8^{a}\end{aligned}$ \\
\hline
\end{tabular}

Means are given with standard errors of the mean $(n=12)$. When values differ significantly from the control group within time intervals, this is indicated as ${ }^{\mathrm{a} P}<0.05$.

concentration was increased with iron deficiency. ${ }^{18,19}$ However, transferrin receptors in plasma were not affected by vitamin A status. In the vitamin A-deficient rats, the blood reticulocyte index was raised at day 12 , but was unaltered at day 70.

The rate of breakdown of red cells was assessed by measuring plasma lactate dehydrogenase activity and plasma total bilirubin concentration. ${ }^{17}$ Lactate dehydrogenase was not affected by the diet, and the bilirubin level was reduced rather than raised after feeding the vitamin A-deficient diet. Thus, vitamin A deficiency cannot be shown to stimulate red cell degradation when measured either indirectly or with radioisotopes, ${ }^{8}$ disproving our hypothesis. This statement seems to be at variance with the observation that iron had accumulated in spleen and especially in bone marrow in the vitamin A-deficient rats. Iron may have been trapped in the macrophages and thus unavailable for heme production, but in that case erythrocyte protoporphyrin should be increased, as a measure of functional iron deficiency ${ }^{20}$ as was seen in the irondeficient rats. With vitamin A deficiency, there was no increase in erythrocyte protoporphyrin concentration so that sufficient iron may have been available for erythropoiesis.

Vitamin A deficiency could reduce transferrin synthesis, as indicated by the low plasma iron-binding capacity. To see whether transferrin glycosylation is affected by vitamin A, microheterogeneity of the transferrin molecules was determined. Vitamin A may assist in glycosylation of transferrin, as has been found in in vitro systems, ${ }^{21,37-39}$ but the mechanism involved is still unclear. We found evidence for enhanced rather than reduced glycosylation in vitamin A deficiency, because the proportion of higher sialylated transferrin was increased. Iron deficiency had a similar influence. The physiologic basis of transferrin microheterogeneity is obscure, but transferrin with low sialic acid content is associated with increased iron turnover and increased iron in hepatocytes. ${ }^{40}$ Thus, a high degree of sialylation could point to iron sparing, which would be feasible for the condition of iron deficiency. However, this is difficult to see in vitamin A deficiency with iron accumulation in macrophages of the reticuloendothelial system. It may be that iron is less available in vitamin A deficiency, which triggers iron sparing. Glycosylation and synthesis of transferrin could be regulated independently ${ }^{41}$ whereas there is evidence that in vitro transferrin gene transcription is stimulated by vitamin $\mathrm{A} .{ }^{42,43}$ Thus, the low plasma iron-binding capacity in vitamin A deficiency could relate to inhibition of transferrin synthesis at the level of transcription.

In conclusion, we have found no evidence for impaired erythropoiesis or increased red blood cell turnover in rats with vitamin A deficiency. However, the dynamic processes were measured only indirectly and qualitatively. Ferrokinetic studies might be more informative. ${ }^{38}$ In this study there was no anemia in vitamin A deficiency, which could have prevented changes in erythropoiesis and erythrocyte turnover. However, the marginal vitamin A deficiency that was induced did lead to the accumulation of iron in spleen and bone marrow.

Table 8 Relative occurrence of sialo-transferrin (Tf) fractions (\%) and the ratio $\frac{1+2 \text { sialo-Tf }}{3+4 \text { sialo-Tf }}$

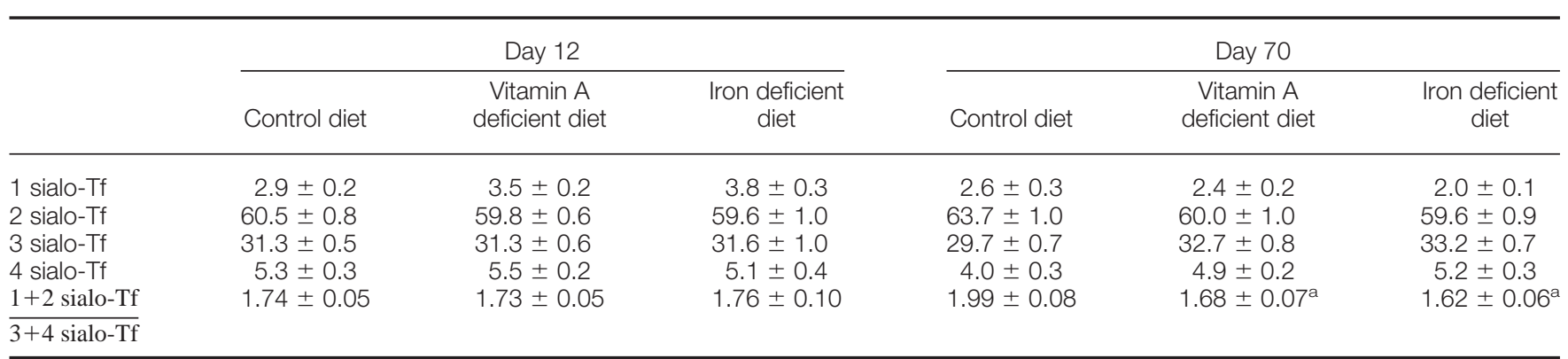

Means are given with standard errors of the mean $(n=10-12)$. When the ratio $\frac{1+2 \text { sialo-Tf }}{3+4 \text { sialo-Tf }}$ differs significantly from the control group at within the time intervals, this is indicated as ap $<0.01$. 


\section{Acknowledgments}

The authors thank Frank van den Broek, Gerrit van Tintelen, Inez Lemmens, Shiguang Yu, Robert Hovenier, Anja Roeling, Anneke Starkenburg, Marja Kuijsten, Rianne Ligterink, Rijma Roozemond, and Corrie Scholtus for technical assistance. Yves Beguin is a Senior Research Associate of the National Fund for Scientific Research (FNSR, Belgium).

\section{References}

1 Mohanram, M., Kulkami, K.A., and Reddy, V. (1977). Hematological studies in vitamin A deficient children. Int. J. Vit. Nutr. Res. 47, 389-393

2 Mejía, L.A., Hodges, R.E., Arroyave G., Viteri F., and Torún, B. (1977). Vitamin A deficiency and anemia in Central American children. Am. J. Clin. Nutr. 30, 1175-1184

3 Bloem, M.W., Wedel, M., Egger, R.J., Speek, A.J., Schrijver, J., Saowakontha, S., and Schreurs, W.H.P. (1989). Iron metabolism and vitamin A deficiency in children in Northeast Thailand. Am. J. Clin. Nutr. 50, 332-338

4 Wolde-Gebriel, Z., West, C.E., Gebru, H., Tadesse, A.S., Fisseha, T., Gabre, P., Ayana, G., and Hautvast, J.G.A.J. (1993). Interrelationship between vitamin A, iodine and iron status in school children in Shoa Region, Central Ethiopia. Br. J. Nutr. 70, 104-114

5 Suharno, D., West, C.E., Muhilal, Logman, M.H.G.M., De Waart, F.G., Karyadi, D., and Hautvast, J.G.A.J. (1992). Cross sectional study on the iron and vitamin A status of pregnant women in West Java, Indonesia. Am. J. Clin. Nutr. 56, 988-993

6 Kolsteren, P., Rahman, S.R., Hilderbrand, K., and Diniz, A. (1999). Treatment for iron deficiency anaemia with combined supplementation of iron, vitamin A and zinc in women of Dinajpur, Bangladesh. Eur. J. Clin. Nutr. 53, 102-106

7 Mejia, L.A., Hodges, R.E., and Rucker, R.B. (1979). Role of vitamin A in the absorption, retention and distribution of iron in the rat. $J$. Nutr. 109, 129-137

8 Gardner, R., Hodges, R., and Rucker R. (1979). Fate of erythrocyte iron in vitamin A deficient rats. Fed. Proc. 38, 762

9 Amine, E.K., Corey, J., Hegsted, D.M., and Hayes, K.C. (1970). Comparative hematology during deficiencies of iron and vitamin A in the rat. J. Nutr. 100, 1033-1040

10 Mejia, L.A., Hodges, R.E., and Rucker, R.B. (1979). Clinical signs of anaemia in vitamin A-deficient rats. Am. J. Clin. Nutr. 32, $1439-1444$

11 Koessler, K.K., Maurer, S., and Loughlin R. (1926). The relation of anaemia, primary and secondary, to vitamin A deficiency. JAMA 87, $476-482$

12 Sijtsma, K.W., Van den Berg, G.J., Lemmens, A.G., West, C.E., and Beynen, A.C. (1993). Iron status in rats fed diets containing marginal amounts of vitamin A. Br. J. Nutr. 70, 777-785

13 Roodenburg, A.J.C., West, C.E., Yu, S., and Beynen, A.C. (1994). Comparison between time-dependent changes in iron metabolism of rats as induced by marginal deficiency of either vitamin A or iron. Br. J. Nutr. 71, 687-699

14 Ahluwalia, N., Mahlon, M., Ross, A.C., Li, N.O., and Ellis, B. (1997). Effect of ageing and chronic vitamin A status on hematological and iron status indices in rat. FASEB J. 11, 1379

15 Roodenburg, A.J.C., West, C.E., Hovenier, R., and Beynen, A.C (1996). Supplemental vitamin A enhances the recovery from iron deficiency in rats with chronic vitamin A deficiency. Br. J. Nutr. 75, 623-636

16 Roodenburg, A.J.C., West, C.E., Hovenier, R., and Beynen, A.C (1995). Evaluation of a two generation rat model for vitamin A deficiency and the inter-relationship with iron metabolism. Br. J. Nutr. 74, 689-700

17 Hoffbrand, A.V. and Pettit, J.E. (1993). Essential Haematology, 3rd ed. Blackwell, Oxford, UK

18 Beguin, Y., Huebers, H.A., Josephson, B., and Finch, C.A. (1988). Transferrin receptors in rat plasma. Proc. Natl. Acad. Sci. 85, 637-640

19 Thorstensen, K. and Romslo, I. (1993). The transferrin receptor: Its diagnostic value and its potential as therapeutic target. Scand. J. Clin. Lab. Invest. 35(suppl 215), 113-120

20 International Nutritional Anemia Consultative Group. (1985). Measurements of Iron Status. The Nutrition Foundation Inc., Washington, DC, USA

21 Chan, V.T. and Wolf, G. (1987). The role of vitamin A in the glycosylation reactions of glycoprotein synthesis in an 'in vitro' system. Biochem. J. 247, 53-62

22 National Research Council. (1978). Nutrient Requirements of Laboratory Animals. National Academy of Sciences, Washington, DC, USA

23 Banecroft, J.D. and Stevens, A. (1990). Theory and Practice of Histological Techniques. Churchill Livingstone, Edinburgh, UK

24 Bannasch, P. and Zerban, H. (1986). Renal cell adenoma and carcinoma, rat. In: ILSI Monographs on Pathology of Laboratory Animals: Urinary System (T.C. Jones, U. Moht, and R.D. Hunt, eds.), pp. 112-139, Springer Verlag, Berlin, Germany

25 Hillman, R.S. and Finch, C.A. (1985). Red Cell Manual. 5th ed. F.A. Davis Company, Philadelphia, PA, USA

26 Van Eijk, H.G. and Van Noort, W.L. (1992). The analysis of human serum transferrins with the PhastSystem: Quantization of microheterogeneity. Electrophoresis 13, 354-358

27 McGarrison, R. (1931). The causation of stone in India. Brit. Med. J. 1, 1009-1015

28 Kancha, R.K. and Anasuya, A. (1990). Effect of vitamin A deficiency on urinary calculus formation in rats. J. Clin. Biochem. Nutr. 8, 51-60

29 Nauss, K.L., Phua, C.C., Ambrogi, L., and Newberne P.M. (1985). Immunological changes during progressive stages of vitamin A deficiency in the rat. J. Nutr. 115, 909-918

30 Wirth, D. (1950). Grundlagen eines Klinischen Hämatologie der Hautiere (Basics in Clinical Hematology of Domestic Animals, (2nd ed.), Urban en Scwarzenberg, Vienna, Austria

31 Bailly, Y. and Duprat, P. (1990). Normal blood cell values, rat. In: ILSI Monographs on Pathology of Laboratory Animals: Hemopoeitic System (T.C. Jones, J.M. Ward, and R.D. Hunt, eds.), pp. 27-38, Springer Verlag, Berlin, Germany

32 Hulse, E.V. (1964). Quantitative cell counts of the bone marrow and blood and their secular variations in the normal adult rat. Acta Haemat. 31, 50-63

33 Ulrich, T.R. and Del Castillo, J. (1991). The hematopoietic and mature blood cells of the rat: Their morphology and the kinetics of circulating leukocytes in control rats. Exp. Hematol. 19, 639-648

34 Loeb, W.F. and Quimby, F.W. (1989). The Clinical Chemistry of Laboratory Animals. Pergamon Press, New York, NY, USA

35 Kimura, H., Finch, C.A., and Adamson, J.W. (1986). Hematopoiesis in the rat: quantization of hematopoietic progenitors and the response to iron deficiency anemia. J. Cell. Physiol. 126, 298-306

36 Bothwell, T., Charlton, R.W., Cook, J.D., and Finch, C.A. (1979). Iron Metabolism in Man. Blackwell, Oxford, UK

37 Rosso, G.C., Bendrick, C.J., and Wolf, G. (1981). In vivo synthesis of lipid-linked oligosaccharides in the livers of normal and vitamin A-deficient rats. J. Biol. Chem. 256, 8341-8347

38 DeLuca, L.M., Brugh, M.R., Silverman-Jones, C.S., and Shidoji, Y. (1982). Synthesis of retinyl phosphate mannose and dolichyl phosphate mannose from endogenous and exogenous retinyl phosphate and dolichyl phosphate in microsomal fraction. Biochem. J. 208, $159-170$

39 Guma, F.C.R. and Bernard, E.A. (1994). Effects of retinol on glycoprotein synthesis by Sertoli cells in culture: Dolichyl phosphomannose synthase activation. Int. J. Androl. 17, 50-55

40 Beguin, Y., Bergamaschi, G., Huebers, H.A., and Finch, C.A. (1988). The behavior of asialotransferrin-iron in the rat. Am. J. Hematol. 29, 204-210

41 De Jong, G., Feelders, R., Van Noort, W.L. and Van Eijk, H.G. (1995). Transferrin microheterogeneity as a probe in normal and disease states. Glycoconj. J. 12, 219-226

42 Hsu, S.L., Lin, Y.F., and Chou, C.K. (1992). Transcriptional regulation of transferrin and albumin genes by retinoic acid in human hepatoma cell line Hep3B. Biochem. J. 283, 611-615

43 Kasza, A., Bungno, M., and Koj, A. (1994). Long-term culture of HepG2 hepatoma cells as a model for liver acute phase response during chronic inflammation. Effects of interleukin-6, dexamethasone and retinoic acid. Biol. Chem. Hoppe-Seyler 375, 779-783 